\title{
CLINICAL COMPARISON OF THE EFFECTIVENESS OF THREE PROPHYLACTIC TOOTHPASTES IN REMOVING DENTAL STAINS
}

\author{
Katarzyna Mocny-Pachońska, Patrycja Jaworowska-Baranowska, Aleksandra Mackiewicz, Izabela Masłowiec, \\ Zuzanna Stochel, Agata Trzcionka, Marta Tanasiewicz
}

Department of Conservative Dentistry with Endodontics, School of Medicine with the Division of Dentistry Medical University of Silesia in Katowice, Poland

\begin{abstract}
INTRODUCTION: Any change in tooth colour to a different colour than natural is considered as discolouration. There are three main types of discoloration: external, internal, and indirect (a combination of the first two). External discolorations are caused by external factors and appear on the surface of the tooth's clinical crown.

ОвJеCтIVEs: The objective of the double-blind clinical study was to compare the efficacy in extrinsic tooth stain removal of three commercially available dentifrices.

MATERIAL AND METHODs: In research, the following products were used: CleanPolish (Kerr), Detartrine (Septodont), and Cleanic (Kerr). The research included a questionnaire and a preliminary study containing a diagram and shortened Lobene Stain Index. The questionnaire contained questions about the habits predisposing to the formation of deposits. Determination of intensity and extent of deposits was made before and after the teeth cleaning procedure. Afterwards, the data was taken and analysed, and the effectiveness of different products was compared. Only anterior teeth were taken into consideration (shortened Lobene Stain Index). The research was conducted with a double-blind method.

RESULTS: All tested dentifrices were well-tolerated. Detartrine was the most effective in removing deposits. However, none of the tested pastes removed stains completely.

ConcLusions: The dentifrices used in the study showed similar effectiveness despite the differences in RDA value and the same clinical conditions, which justifies the need in the subsequent steps of the study of usage of a more sensitive and specific modified stain index (MSI).
\end{abstract}

KEY wORDS: prophylaxis, toothpastes, dental stains, Lobene Stain Index.

J Stoma 2019; 72, 2: 58-62

DOI: https://

\section{INTRODUCTION}

Any state of change in tooth colour to one other than natural is considered as discolouration $[3,10]$. Changes in the nature of discoloration may be caused by a number of different factors, and we can divide them according to their appearance, durability, location, and treatment options. There are three main types of discoloration: external, internal, and indirect (a combination of the first two). External discolorations are caused by external factors and appear on the surface of the tooth's clinical crown. Endogenous systemic discolouration results from taking tetracycline antibiotics during odontogenesis, general
JOURNAL OF STOMATOLOGY CZASOPISMO STOMATOLOGICZNE
AdDRESS FOR CORRESPONDENCE: Katarzyna Mocny-Pachońska, PhD, Department of Conservative Dentistry with Endodontics School of Medicine with the Division of Dentistry Medical University of Silesia in Katowice, Pl. Akademicki, 41-902 Bytom, Poland, e-mail: kpachonska@sum.edu.pl

RECEIVED: 20.01.2019 • ACCEPTED: 02.07.2019 • PUBlished: 19.07.2019 
diseases (thyroid and pituitary gland disorders or genetic diseases, i.e. porphyria), dental malformations, or fluoride poisoning $[3,11,16]$. Local endogenous discolouration is caused by structural changes of tooth tissues associated with the ageing process of the organism and pathological conditions of the pulp, which often result from tooth injuries (internal bleeding, chamber mineralisation). It may also be caused by root filling materials and reconstruction of tissues lost as a result of caries, e.g. filled with amalgam [11].

Factors that favour the formation of external discolourations are mainly: defects of enamel, composition of saliva and its limited or altered flow, and insufficient oral hygiene. The appearance of discolouration on the surface of tooth tissues is often associated with the use by patients of certain stimulants (mainly tobacco), medicines (chlorhexidine or tin salts), and the consumption of staining drinks (coffee, tea). The source of dyes may also be metabolites of oral bacteria (Neisseria, Porphyromonas, Actinomyces) $[1,3,6,8,11,16]$.

There are two major approaches to removing the stains, including the chemical mechanism using peroxides for tooth bleaching and the mechanical mechanism using abrasives in prophylactic pastes and dentifrices to remove stains, resulting in a whitening effect. Attempts have also been made to add a low concentration of peroxides to dentifrices to enhance their abrasive cleaning to remove tooth stains [17].

\section{OBJECTIVES}

The objective of this double-blind clinical study was to compare the efficacy in extrinsic tooth stain removal of three commercially available dentifrices.

\section{MATERIAL AND METHODS}

The purpose of the research was an assessment of the effectiveness of three commercially available dentifrices used in the professional cleaning procedure. The research was conducted on patients of the Dental Clinic of the Department of Conservative Dentistry with Endodontics of the Medical University of Silesia (the Academic Centre of Dentistry and Specialist Medicine in Bytom). The choice of dentifrices used in the experiment was dictated by their widespread use and availability in the Dental Clinic where the study was conducted, which depended on the expectations of the medical staff using these resources. The research programme was approved by the Bioethics Committee of the Silesian Chamber of Medicine (resolution no. KNW/0022/KB1/19a/12, 06.03.2012). The study consisted of a questionnaire and an examination.

Initially, a group of 38 patients was invited to take part in the experiment, in whom the preliminary study and assessment of habits were conducted on the basis of a questionnaire. Each patient received a questionnaire to complete, which contained 12 questions. The questions concerned, among others: age, gender, and education. The questionnaire also contained queries about habits and used stimulants that could have an influence on the formation of external discolouration on teeth, such as drinking coffee, tea, or red wine or smoking cigarettes. There were also questions about hygienic habits, for example: the frequency of brushing teeth or the frequency of visits to the dentist. In order to unify the study group, on the basis of the survey results, patients who indicated extreme (negative) answers to at least 6 out of 12 questions (those affecting the increased accumulation of the discolorations such as smoking more than five cigarettes per day) were excluded. Final criteria of exclusion from the study included: patients who did not express consent to take part in the research, juvenile patients, toothless patients, pregnant women, patients undergoing therapy against acute systemic diseases, patients with acute periodontal diseases, and patients with recorded dentinal hypersensitivity. Strict eligibility criteria based on both the introductory examination and the results of the questionnaire resulted in a small number of patients (but comparable and statistically standardised). After that the research group comprised 28 adult patients, both women and men. In the clinical trial a diagram was made, in which defects, fillings, and missing teeth were marked.

The next step was to determine the extent and intensity of the sediments according to the short Lobene Stain Index [8]. Six front teeth, both upper and lower, were assessed. The study excluded teeth with fillings, crowns, braces, or tartar. Sediment assessments were made in artificial lighting using a unit lamp without prior drying. The colour intensity of the deposit was determined as follows:

- no. 0: no stains, natural tooth colouration,

- no. 1: colours from yellow to light brown or grey,

- no. 2: brown-coloured deposits,

- no. 3 dark-brown to black deposits.

The range is outlined in a diagram on a three-point scale (separately for the labial and lingual/palatal surface):

- 1: deposit covers one third of the surface,

- 2: deposit covers two thirds of the surface,

- 3: deposit covers the whole surface.

According to the short Lobene Stain Index (SI), following the assessment of intensity and range, a further four people (who were found to have "SI no. 0: no stains, natural tooth colouration") were excluded from the group.

The final group of 24 patients was randomly divided into three subgroups, in which the following pastes were used:

1. Cleanic Prophy Paste (Kerr) with RDA (relative dentin abrasivity) $=27$, in which silicates (perlite particles) were the abrasive compounds,

2. Clean Polish Paste (Kerr) with $\mathrm{RDA}=43.8$, in which pumice, clay, and calcium carbonate were the abrasive compounds, 
3. Detartrine (Septodont) - containing silica and 35\% formaldehyde, the RDA of which was 150 .

In the case of each patient, the tooth cleaning procedure was performed with a Pro-Cup (Kerr) brush set powered by a micromotor, at a constant speed (5000 rpm), with the same operational time of about seven minutes. The amount of paste defined as "one portion" was determined by the volume of the dentifrices similar to the pea grain/volume and not falling from the Pro-Cup brush head. The purification procedure was performed identically in all groups in terms of time, technique, instruments, and amount of dentifrices. Then, the Lobene Stain Index was established. Each paste was tested on eight volunteers. Two sums were calculated for the Lobene Stain Index: the sum of intensity (the sum of all intensity results for a given tooth divided by the number of tooth surfaces) and the sum of the deposit range (the sum of areas covered with deposit, assessed from 1 to 3 for each surface, then divided by the number of the tooth surface). The deposit assessment was carried out by one trained person who did not know which paste was used in the given case. The data was analysed with the Student's $t$-test. A value of $p<0.05$ was considered statistically significant.

\section{RESULTS}

Finally the study involved 24 adult volunteers, two thirds of whom were women. The majority of patients were in the 18-25-year age range (11 people); four patients were more than 55 years old. Nearly $60 \%$ of them had secondary education. The survey showed that all patients brushed their teeth. Twenty of the respondents used brushes with medium hardness of the bristles, three used a soft brush, and only one of the respondents used a hard toothbrush. $46 \%$ of people brushed their teeth three times a day, 33\% - two times a day, and only one person - once every two days. Most of the studied patients used anti-caries pastes (37.5\%) and those aimed at providing comprehensive protection (33\%). However, only a few used herbal pastes (4\%) or pastes for smokers (4\%). $29 \%$ of patients used whitening pastes, $25 \%$ pastes for hypersensitivity. As for additional oral hygiene items, over two thirds of the respondents declared that they used them. The most commonly used items were as follows: mouthwashes (12 people) and dental floss (10 people). However, none of the respondents used dental irrigators for daily hygiene, while only two used interdental brushes. Twenty-two people drank black tea: seven people twice a day, five - once a day, five - three times a day, three - four times a day, and two patients - five times a day. Eighteen of the respondents drank black coffee, including six people who drank it twice a day. Twelve people drank green tea, including seven who drank it only once a day. Eleven people admitted to drinking wine occasionally. One third of the surveyed patients reported smoking cigarettes. Respondents also answered questions about the frequency of dental visits, as well as whether they had ever had professional hygiene or whitening procedures performed. Only one of 24 patients visited the dentist every three months, another nine people - every six months, five - once a year, and the others less often than once a year. The survey also included questions about such treatments as scaling, sandblasting, and whitening. More than half the people had had a calculus removal procedure, only six people had undergone sandblasting in the past, and three people had undergone whitening treatment (Figure 1).

In the clinical study of all pastes, the deposit index and its components (intensity and area) significantly decreased.

After applying the Cleanic paste, the intensity of the deposit statistically significantly decreased (Student's independent $t$-test $[p=0.0017]$ with the assumed level of significance $\alpha=0.05$ ). After using Cleanpolish, the intensity of the deposit statistically significantly decreased (Student's independent $t$-test [ $p=0.0020]$, with the assumed level of significance $\alpha=0.05$ ). After applying the Detartrine paste, the intensity of the deposit statistically, significantly decreased (Student's independent $t$-test $[p=0.0038]$, with the assumed level of significance $\alpha=0.05$ ) (Figure 2).

After applying the Cleanic Prophy Paste, the extent of the deposit statistically, significantly decreased (Student's dependent $t$-test $[p<0.0001]$ with the assumed level of significance $\alpha=0.05)$. After applying Clean Polish Paste, the extent of the deposit statistically, significantly decreased (Student's dependent $t$-test [ $p=0.0033]$, with the assumed level of significance $\alpha=0.05$ ). After applying the Detartrine paste, the extent of the deposit statistically significantly decreased (Student's dependent $t$-test $[p<0.0001]$, with the assumed level of significance

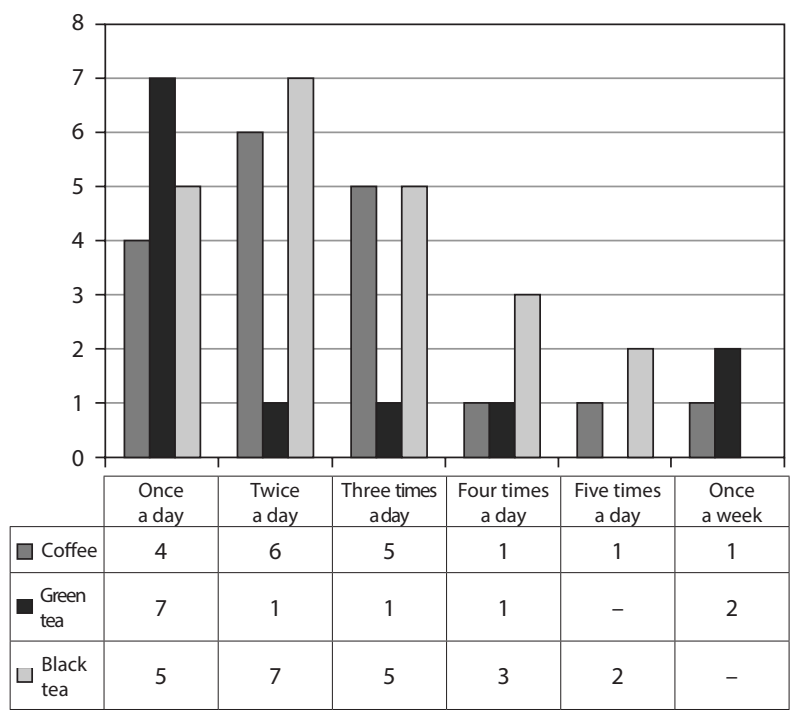

FIGURE 1. The results of the survey question regarding the frequency of consumption of beverages 


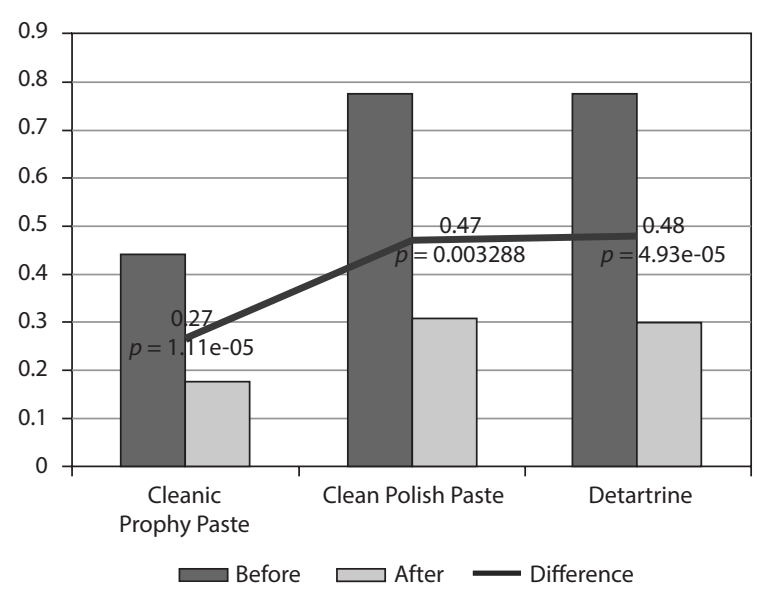

FIGURE 2. Average values of stain area

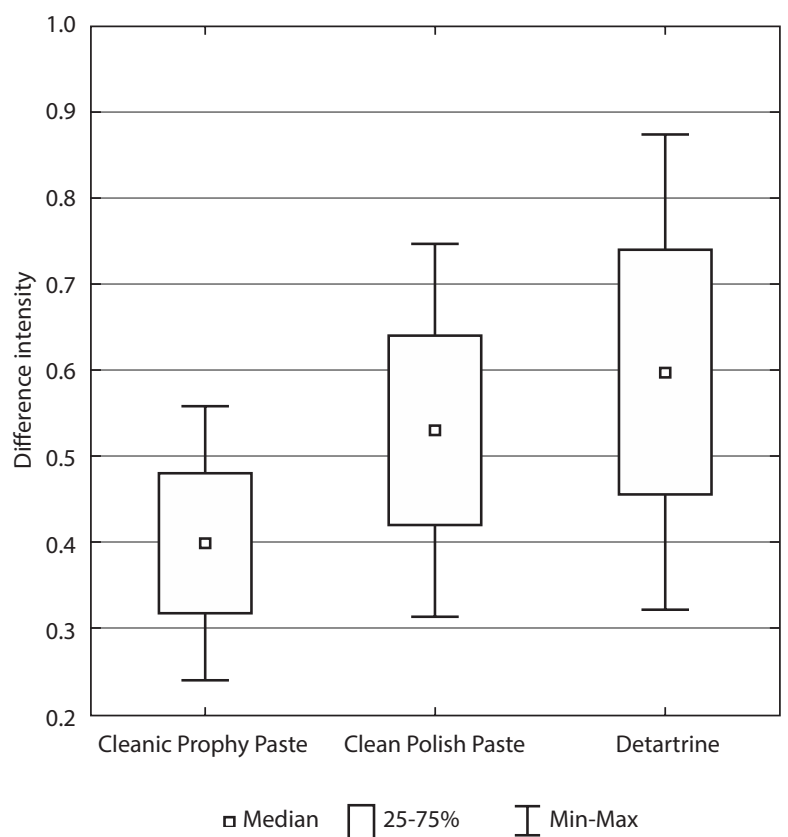

FIGURE 4. Comparison of differences in deposit intensity for each paste

$a=0.05$ ) (Figure 3). The average difference in the intensity of discolouration and the extent of the deposit before and after the treatment was the highest for the Detartrine paste.

There was no statistically significant difference in intensity after application of the pastes (F test for one-way analysis of variance $[p=0.4682]$, with the assumed significance level $\alpha=0.05$ ) (Figure 4 ). A statistically significant difference in the range after applying the pastes was demonstrated (Kruskal-Wallis test $[p=0.0233]$, with the assumed significance level $\alpha=0.05$ ). Further posthoc analysis showed a statistically significant difference between Cleanic Prophy Paste and Detartrine (Figure 5).

Changes in deposit intensity did not differ significantly between pastes. Studies have shown that the Detartrine paste statistically significantly reduced the extent

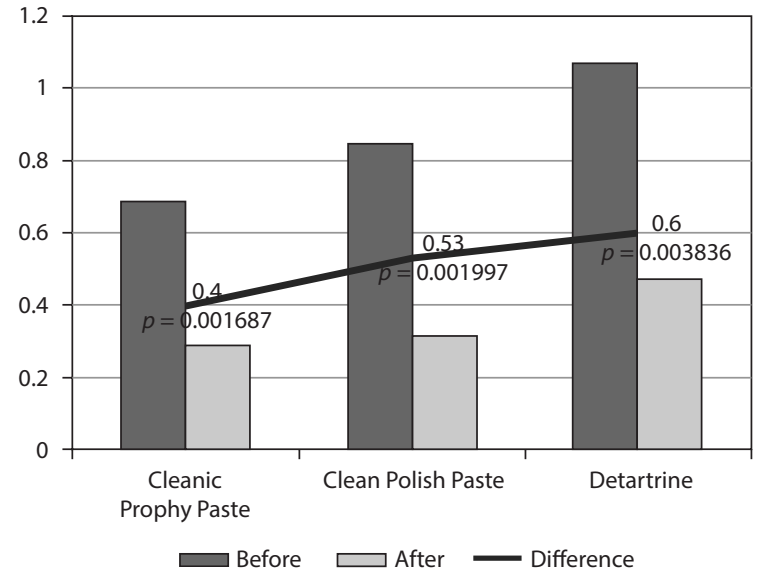

FIGURE 3. Average values of stain intensity

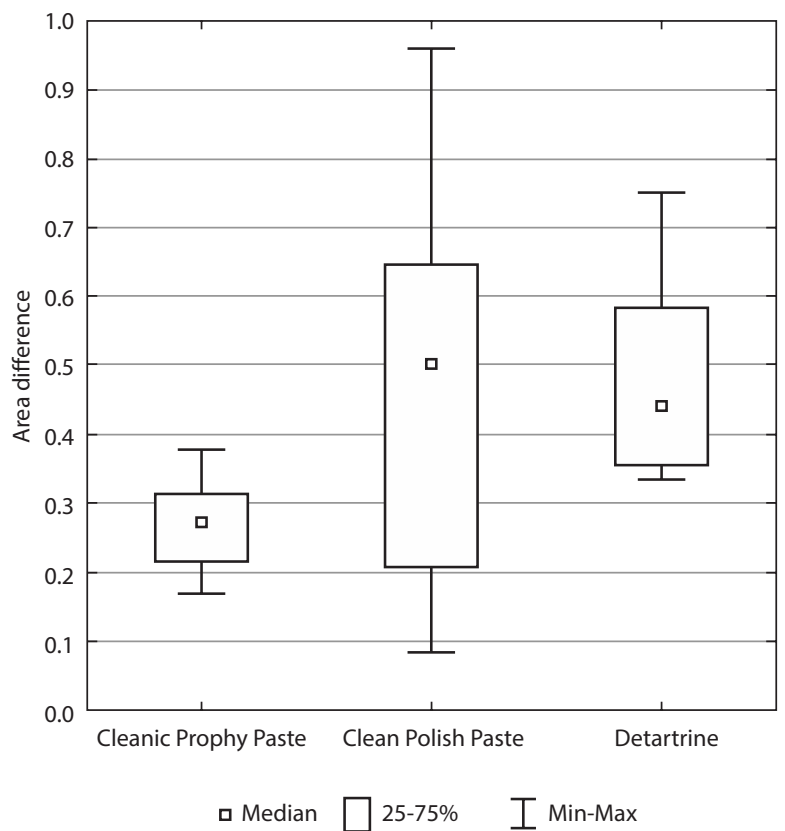

FIGURE 5. Comparison of deposit range differences for each paste

of the deposit in comparison to the Cleanic Prophy Paste. In most patients, Detatrine also caused tooth hypersensitivity occurring after the cleaning procedure, reported as an unpleasant feeling of cold during mouthwashing and disappearing within 10-15 minutes.

\section{DISCUSSION}

On the market of dental materials intended for use in the dental office there are many pastes for professionally cleaning teeth of extrinsic stains. An important function of a dentifrice is the control of extrinsic tooth discoloration caused by certain dietary components, tobacco, or drugs that are associated with protein compounds found in enamel structure and surface $[6,17]$. 
It is assumed that pastes differing in the degree of abrasion may differ in effectiveness, rate of stain removal, intensity of complications, and unexpected side effects in the form of dental hypersensitivity, scratches of enamel, irritation of the marginal periodontium, increase in the intensity of stain deposition, and increase of the resistance to plaque and deposit accumulation in shorter intervals [7, 13]. Stopa et al. determined the abrasive properties of Detartrine, Nupro, Protect, Prophylaxis, pumice, zinc oxide, glycerol pastes, and a standard paste, and emphasised that it should be considered that use of highly abrasive smoothing agents at short intervals can lead to microdamage of enamel and cement [14]. Equally important is the micromotor speed and pressure of the operator, the kind of the brush used, and the use of a water spray. The higher the speed and pressure, the greater the abrasion and heat generation, which can lead to dental hypersensitivity or pulp damage [4]. In the case of the presented study professional dentifrices of different abrasion values were used, but the uniformity of the examination conditions (one operator, equal portion of the paste, the same working time, water cooling, and the same ancillary tools) meant that all the products proved to be effective. Similar results were obtained by Young et al., who highlighted the importance of the previously mentioned additional factors [18]. Watts, Addy, and Johannsen pointed to the importance of the additional ingredients present in the dentifrice composition, such as silicon oil, which makes the surface of the abraded material smoother and reduces the abrasive effect $[5,17]$.

The use of a simple, sensitive, and specific index for the clinical evaluation is an extremely important factor in the evaluation of the efficacy of professional products intended for the removal of the extrinsic stains. The most commonly used is the Lobene Stain Index (SI) [8]. This index is used both in long-term clinical studies of toothpastes that patients use at home $[4-6,18]$, manual or sonic brushes [2], mouthrinses [15], or chewing gums [12] for cleaning the teeth of deposits and discolorations, similarly to the dentifrices evaluated in the presented study. However, there are literature reports indicating the need to compare its sensitivity and specificity with the tooth stain index modified by Macpherson. This involved assigning separate scores to the mesial and distal sites of each tooth in addition to the standard gingival area and tooth body. For each site, stain intensity and areas are scored [9]. The use of the modified index may justify the clinical effectiveness of dentifrices with lower abrasive properties but with smaller abrasive components, and thus better penetration into mesial and distal spaces, which are omitted by the conventional index.

\section{CONCLUSIONS}

The dentifrices used in the study showed similar effectiveness despite the differences in RDA value and the same clinical conditions, which justifies the need of a more sensitive and specific, Modified Stain Index (MSI) in subsequent steps of the study.

\section{CONFLICT OF INTEREST}

The authors declare no potential conflicts of interest with respect to the research, authorship, and/or publication of this article.

\section{References}

1. Gadhia K, Shah R, Wetton S, Moran J, Swaminatha D. Development of a stain shade guide to aid the measurement of extrinsic dental stain. Int J Dent Hyg 2006; 4: 98-103.

2. Goyal CR, Klukowska M, Grender JM, Cunningham P, Qaqish J. Evaluation of a new multi-directional power toothbrush versus a marketed sonic toothbrush on plaque and gingivitis efficacy. Am J Dent 2012; 25 SpecNoA(A): 21-26.

3. Hattab FN, Queimat MA, Al-Rimawi HS. Dental discoloration: an overwiev. J Est Dent 1999; 11: 291-310.

4. Johannsen G, Tellefsen G, Johannsen A, Liljeborg A. The importance of measuring toothpaste abrasivity in both a quantitative and qualitative way. Acta Odontol Scand 2013; 71: 508-517.

5. Johannsen G. The influence of silicone oil in toothpastes on abrasion in vitro. Swed Dent J 1993; 17: 117-122.

6. Khan MK, Bokhari SA, Haleem A, et al. Extrinsic stain removal with a toothpowder: A randomized controlled trial. Int J Health Sci 2014; 8: 269-274.

7. Li Y. Stain removal and whitening by baking soda dentifrice: a review of literature. J Am Dent Assoc 2017; 148: 520-526.

8. Lobene RR. Effect of dentifrices on tooth stains with controlled brushing. J Am Dent 1968; 77: 849-855.

9. Macpherson LMD, Stephen KW, Joiner A, Schäfer F, Huntington E. Comparison of a conventional and modified tooth stain index. J Clin Periodontol 2000; 27: 854-859.

10. Małkiewicz K, Jodkowska E. Zaburzenia barwy zębów spowodowane czynnikami pochodzenia wewnętrznego - metody leczenia za pomocą środków wybielających na podstawie przeglądu piśmiennictwa i własnych obserwacji. Nowa Stomatol 2005; 2: 89-93.

11. Nathoo SA. The chemistry and mechanisms of extrinsic and intrinsic discoloration. JADA 1997; 128: 6-10.

12. Porciani PF, Grandini S, Perra C, Grandini R. Whitening effect by stain inhibition from a chewing gum with sodium hexametaphosphate in a controlled twelve-week single-blind trial. J Clin Dent 2006; 17: 14-16

13. Seget-Bieniasz A, Szeląg N. Cechy past polerskich i sposób ich stosowania na przykładzie past Prophy CCS i Prophy PRO firmy Directa. Asyst Hig Stomatol 2016; 41: 28-32.

14. Stopa J, Matthews-Brzozowska T, Górski Z, Jóźwiak K. Ocena właściwości ściernych oraz obrazu ultrastrukturalnego różnych środków służących do profesjonalnego oczyszczania zębów. Czas Stomatol 1994; 47: 446-452.

15. Van Strydonck DA, Slot DE, Van der Velden U, Van der Weijden F. Effect of a chlorhexidine mouthrinse on plaque, gingival inflammation and staining in gingivitis patients: a systematic review. J Clin Periodontol 2012; 39: 1042-1055.

16. Wang C, Lucas R, Smith A, Cooper P. An in vitro screening assay for stain cleaning. BMC Oral Health 2017; 17: 37.

17. Watts A, Addy M. Tooth discolouration and staining: a review of the literature. Br Dent J 2001; 190: 309-316.

18. Young S, Parkinson C, Hall C, Wang N, Milleman JL, Milleman KR. A randomized clinical study investigating the stain-removal potential of two experimental dentifrices. J Clin Dent 2015; 26: 96-103. 